\title{
ANNUAL VAPOR, PRECIPITATION, GROUNDWATER, AND TRANSPIRATION FLUCTUATIONS IN SIMPLE WATER CYCLE PROCESSES
}

\author{
KOJI TAMAI \\ Forestry and Forest Products Research Institute, Japan
}

\begin{abstract}
Cambodia has been actively developing its land use from forests to farmland or plantations. As a result, population, plantations, and agricultural land are increasing and the water resources must depend on groundwater. Therefore, the importance of groundwater as a water resource is increasing. Annual fluctuations of simple water cycle processes, with transitions from vapor in the atmosphere to groundwater, and transpiration processes that release soil water to the atmosphere are interesting to consider when assessing stable use of groundwater. The results of the monitoring data of simple water cycle processes I Kampong Thom, central Cambodia, show that the annual precipitation depends on the number of high-precipitation events rather than on the number of annual precipitation observation days and the dry evergreen forest examined for this study was judged as consuming water to the greatest extent potential with no restrictions. It is concluded that groundwater is useful for stability even if dry evergreen forests are developed into plantations and agricultural lands.
\end{abstract}

Keywords: monitoring data, dry and rainy monsoon, dry season, dry evergreen forest.

\section{INTRODUCTION}

In recent years, Cambodia has been actively developing its land use from forests to farmland or plantations. In Kampong Thom Province, the momentum is especially remarkable. In this area, the sediment carried by the Mekong River is deposited thickly, in many places reaching around $10 \mathrm{~m}$ (Ohnuki et al. [1]). Because large amounts of water can be stored in the soil, it is an area with few natural rivers where water flows on the surface. As a result, population, plantations, and agricultural land are increasing, even in areas (Fig. 1) that are several tens of kilometres distant from natural rivers. In such cases, the water resources must depend on groundwater. Therefore, the importance of groundwater as a water resource is increasing.

The tendency is even stronger in the dry season, when there is little precipitation from December through April. Precipitation, which is the source of groundwater, is brought about by southwest monsoons during the rainy season. Water in Cambodia becomes soil water and groundwater through vapor and precipitation that are borne with the southwest monsoon. Furthermore, part of the soil water is consumed by the transpiration activity of the remaining forest trees. Annual fluctuations of simple water cycle processes, with transitions from vapor in the atmosphere to groundwater, and transpiration processes that release soil water to the atmosphere are interesting to consider when assessing stable use of groundwater. Therefore, comparisons of annual fluctuations on meteorologically significant dates (e.g. the beginning of the monsoon, the rainy season, and the dry season), annual precipitation, evapotranspiration from forests, groundwater level, and other matters are reviewed and discussed herein to assess groundwater stability as a water resource.

\section{OBSERVATION}

For this study, meteorological data and the groundwater level were observed at a $60-\mathrm{m}$ weather observation tower site in the $\mathrm{O}$ Thom I watershed $\left(12^{\circ} 44^{\prime} \mathrm{N}, 105^{\circ} 28^{\prime} \mathrm{E}, 88 \mathrm{~m}\right.$ asl $)$ in 
Kampong Thom Province, central Cambodia. Meteorological data have been stored there every $10 \mathrm{~min}$. The groundwater level was measured manually once daily at the well with 10 $\mathrm{m}$ depth. The forest around the tower, categorized as "dry evergreen forest", consists of evergreen trees with tree density of 1600 stems ha $^{-1}$. The average canopy surface height $(\mathrm{h})$ is $27.2 \mathrm{~m}$. However, there are several emergent trees taller than $35 \mathrm{~m}$ occur per hectare (Shimizu et al. [2])

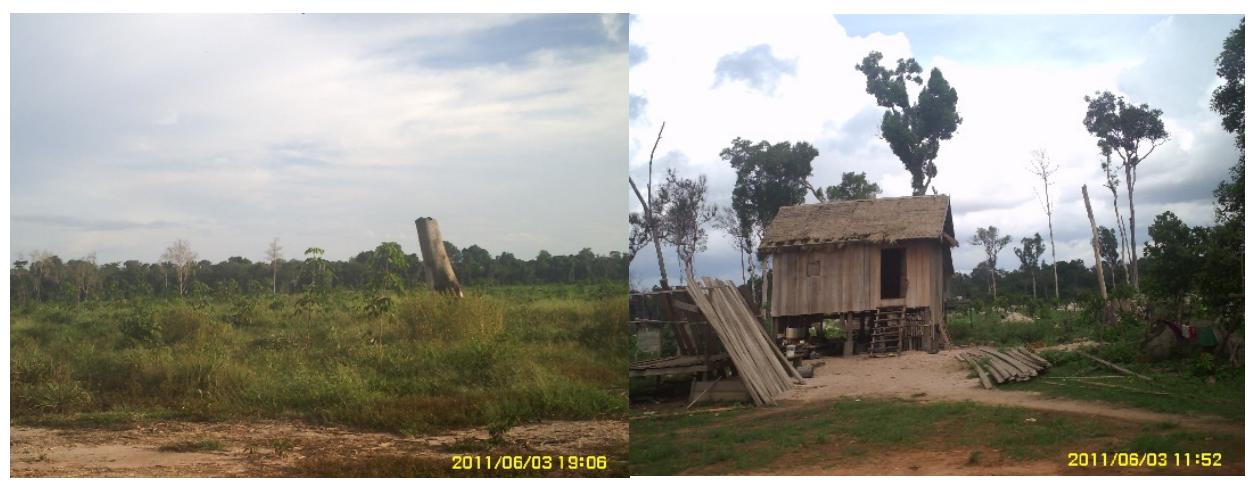

Figure 1: Conversion from dry evergreen forest to rubber plantations (left) and cassava farmland (right) in Kampong Thom Province, Cambodia.

\section{METHOD}

3.1 Determination of the beginning dates of dry and rainy monsoons and dry and rainy seasons

Wind direction data were used to ascertain the beginning dates of dry and rainy monsoon seasons as followings (Nang et al. [3]). Fig. 2 presents aggregated results for 2007 as an example.

1) Wind direction data were categorized as dry monsoon (northeast-northwest), wet monsoon (west-south), and others (southeast-east).

2) The proportion of each category was calculated for each day.

3) Proportions over 50\% for the dry monsoon ( $\square$ ) and wet monsoon (•) are shown in Fig. 2.

4) Periods with high density of $\square$ and $\bullet$ respectively show that the dry monsoon and wet monsoon are predominant.

5) In Fig. 2, the beginning date of the rainy and the dry monsoon were determined from the distribution of $\square$ and $\bullet$; they are indicated respectively by a solid arrow and a broken arrow.

Precipitation data were used as follows to ascertain the initial dates of dry and rainy seasons.

1) Accumulated precipitation lines are depicted in Fig. 2.

2) Lines with a steep decline (thick line) and a gentle decline (thin line) are inferred as respectively representing the dry and rainy seasons.

3) Right and left ends of the thick line were regarded respectively as the beginnings of the rainy and the dry seasons. 


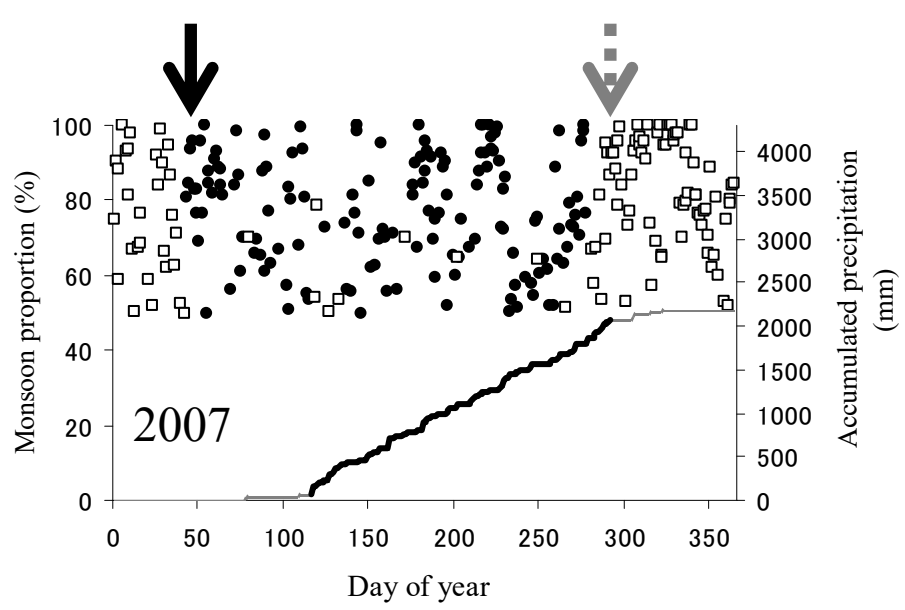

Figure 2: Wind direction and precipitation data analysis to judge the periods of dry and rainy seasons and monsoons in 2007 [3].

3.2 Estimation of evapotranspiration and potential evaporation rates from the evergreen forest

Evapotranspiration rate $(E)$ is obtained using the Bowen ratio method expressed as

$$
\begin{gathered}
\lambda \mathrm{E}=\left(R_{n}-\mathrm{G}\right) /(1+\text { Bowen }) \\
\text { Bowen }=\gamma\left(\mathrm{TD}_{1}-\mathrm{TD}_{2}\right) / \mathrm{C} \\
\mathrm{C}=(\Delta+\gamma)\left(\mathrm{TW}_{1}-\mathrm{TW}_{2}\right)-\gamma\left(\mathrm{TD}_{1}-\mathrm{TD}_{2}\right)
\end{gathered}
$$

where $\lambda$ represents the heat of vaporization of water, Bowen is the Bowen ratio, $\gamma$ stands for the psychrometer formula to be $0.66 \mathrm{hPa}^{\circ} \mathrm{C}^{-1}$ and $\Delta$ denotes the slope of the saturated water vapor pressure curve when the vertical axis is the saturated water vapor pressure and the horizontal axis is the temperature. Also, $\mathrm{TD}_{i}$ and $\mathrm{TW}_{i}$ respectively represent the ventilated dry and wet bulb temperatures $(i=1$ and 2 respectively denote the higher and lower observation height, $R_{n}$ expresses the net radiation, and $G$ stands for the soil heat flux observed as the meteorological data.

The potential evaporation rate $\left(E_{p}\right)$, indicating the climatic conditions that enforce evaporation from the water surface, is calculated with the Penman [4] equation expressed as

$$
\begin{gathered}
l E_{p}=\frac{\Delta\left(R_{n}-G\right)}{(\Delta+\gamma)}+\frac{\Delta}{\Delta+\gamma} f(u) V P D \\
f(u)=0.26(1.0+0.537 u)
\end{gathered}
$$

where $u$ denotes the wind speed and VPD represents the vapor pressure deficit calculated with $\mathrm{TW}_{1}$ and $\mathrm{TD}_{1}$. Also, $E_{p}$ is an index of the temporal variation of the climatic conditions that force evaporation. 


\section{RESULTS AND DISCUSSION}

\subsection{Seasonal course of absolute humidity}

Fig. 3 shows the seasonal course of absolute humidity in 2004-2011. In each figure, $\diamond, \diamond$, $\boldsymbol{\Delta}$, and $\Delta$ respectively denote the beginning date of rainy monsoon, rainy season, dry monsoon, and dry season, with the method explained in III-1. The daily average absolute humidity in the rainy season was not only larger than that in the dry season, but also day-today fluctuated less. Even more interesting is that the diamond or triangle dots are not located at the trend change points of seasonal course, but in the middle of an increasing or decreasing trend of absolute humidity: results show that the amount of water vapor in the air does not change drastically depending on the change of the monsoon and the presence or absence of precipitation.

4.2 Year-to-year fluctuations at the beginning date of rainy and dry monsoon and rainy and dry seasons

Fig. 4 shows the beginning dates of rainy and dry monsoon and rainy and dry seasons, as reported by Nang et al. [3]. Symbols of dots have the same meaning as those of Fig. 2. At the change from the dry to rainy season, $\diamond$ and $\diamond$ occur respectively over widely various DOY 25-95 and DOY 85-120. The time lags between $\diamond$ and $\diamond$ are also long, ranging from 10-80 days.

In contrast, at the changes from the rainy season to the dry season, $\boldsymbol{\Delta}$ and $\Delta$ occur respectively over a much narrower range of DOY 275-295 and DOY 285-310. Time lags between the beginning date of dry monsoon and dry season are also short or are absent, as shown for 2010 and 2011. The results presented above indicate that the change from the dry to the rainy season occurs in steps. The date of the change in season varies widely. However, the change from the rainy to the dry season is clearer. It occurs over a shorter time period. The date of the change in season determined from precipitation data was fixed at around DOY 290.

\subsection{Year-to-year fluctuations of the precipitation amount}

Year-to-year fluctuations in annual precipitation were compared for four years. The annual precipitation was high at $2100.0 \mathrm{~mm}$ and $1885.4 \mathrm{~mm}$ in 2007 and 2011, respectively, and low at $1138.0 \mathrm{~mm}$ in 2010 , respectively.

Fig. 5 shows the number of precipitation observation days (x-axis) and the change in cumulative precipitation (Y-axis) as the number of days increases. The right end of each line shows the number of annual precipitation observation days (X-axis) and the annual precipitation (y-axis). Both the number of annual precipitation observation days and the annual precipitation in 2007 are the lowest in the four years. However, the annual precipitation in 2008, when the number of annual precipitation observation days was the highest, was lower than in 2007 and 2011.

Figure 6 shows values of daily precipitation arranged in ascending order. Therein, $\diamond$ stands for the value of daily precipitation that was $50 \mathrm{~mm}$ day- 1 or more. The numbers of days when the daily precipitation was $50 \mathrm{~mm}$ or more were 1 day in 2010, 3 days in 2008, 9 days in 2007, and 7 days in 2011, which are of almost identical order to the amount of annual precipitation. Especially in 2011, when the annual rainfall was the second highest, 

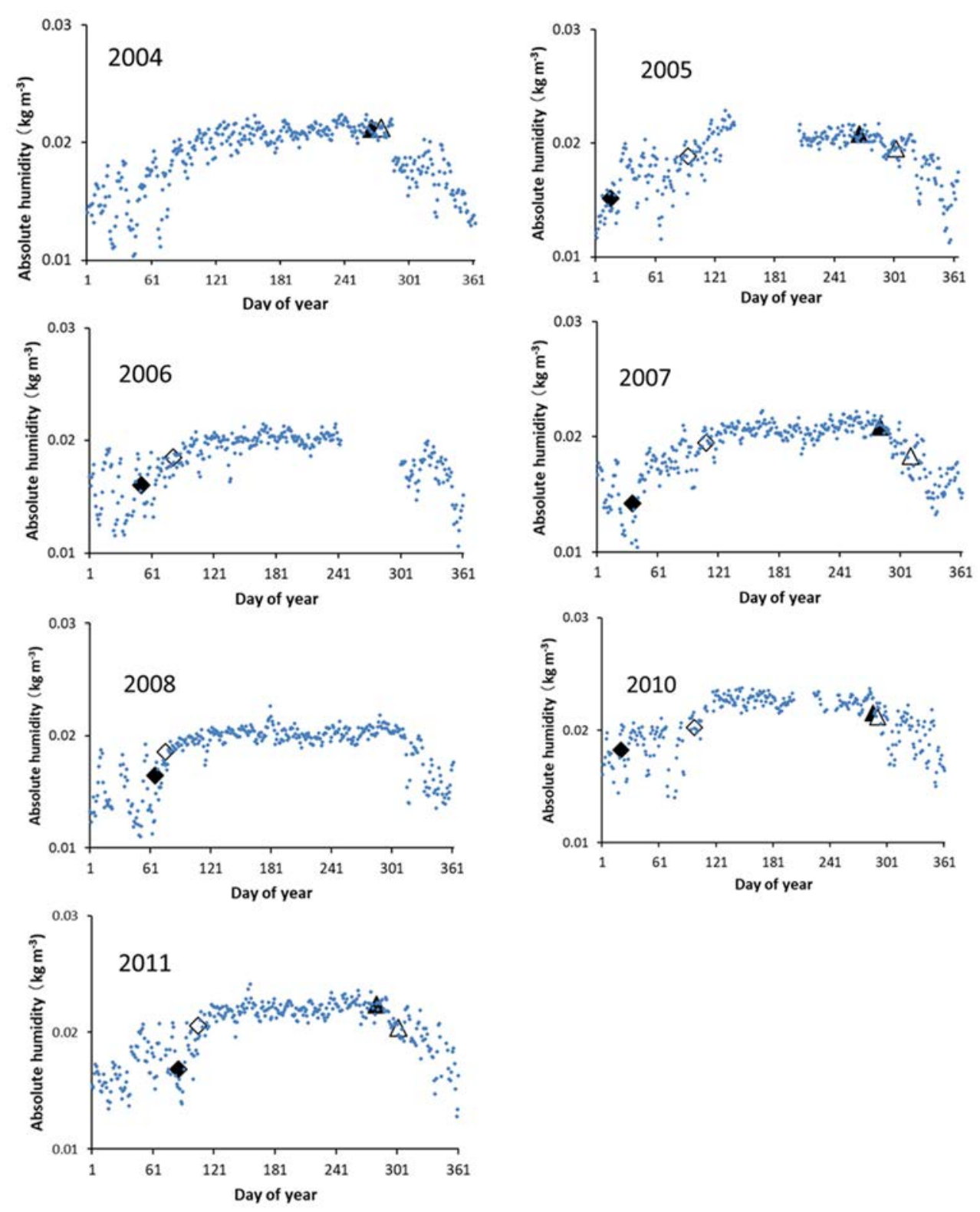

Figure 3: Seasonal course of absolute humidity in 2004-2011. In each figure, $\diamond, \diamond, \boldsymbol{\Delta}$, and $\triangle$ respectively denote the beginning date of rainy monsoon, rainy season, dry monsoon, and dry season, with the method explained in Section 3.1.

there was a day with a particularly high daily rainfall of $138.4 \mathrm{~mm}$. Based on the data presented above, results show that the annual precipitation depends on the number of highprecipitation events rather than on the number of annual precipitation observation days. 

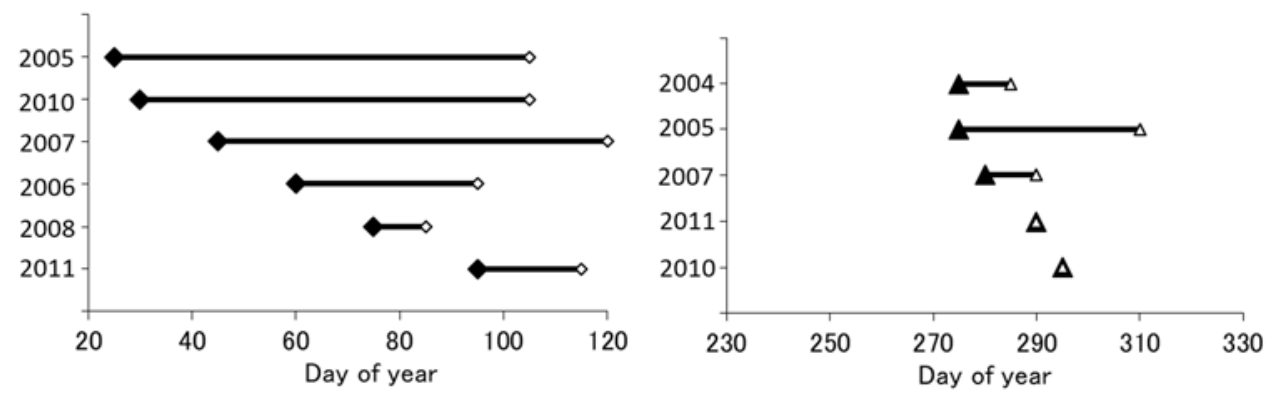

Figure 4: Beginning dates of rainy monsoon and rainy season (left) and dry monsoon and dry season (right). $\diamond, \diamond, \boldsymbol{\Delta}$, and $\Delta$ respectively denote the beginning date of rainy monsoon, rainy season, dry monsoon, and dry season [3].

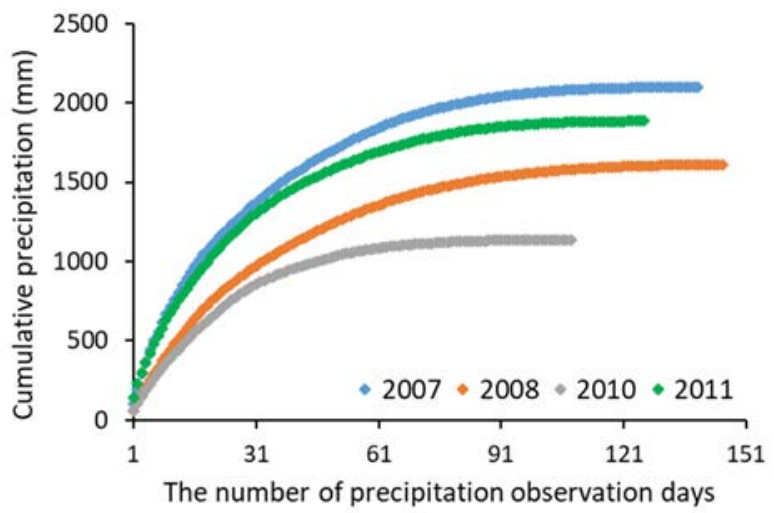

Figure 5: Change in cumulative precipitation as the precipitation observation days increases.

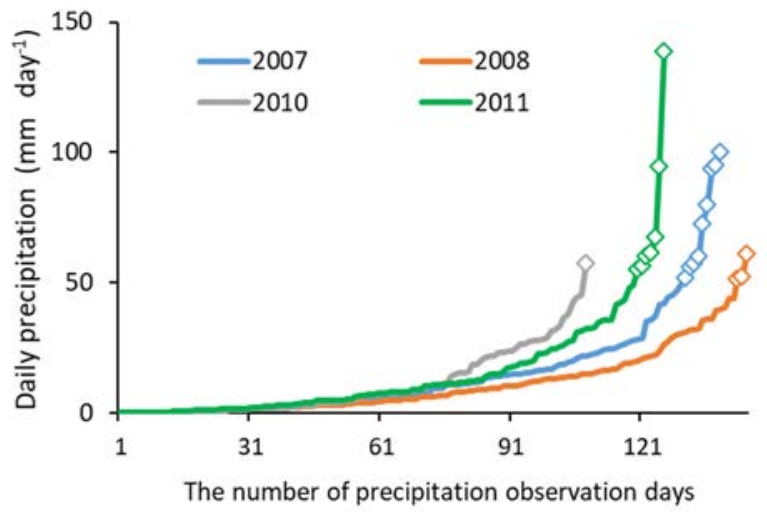

Figure 6: Values of daily precipitation arranged in ascending order. White diamonds stand the value of daily precipitation that was $50 \mathrm{~mm}$ day- 1 or more. 


\subsection{Seasonal course of precipitation and groundwater level}

The monthly precipitation, monthly averaged groundwater level, monthly averaged Ep and monthly averaged E are shown respectively in Fig. 7 for 2004-2007. Moreover, the averaged rates (ARs) and standard deviations (SDs) were calculated with these monthly rates in each month. The year-to-year variation in each monthly value was compared with the AR and SD. In each panel of Fig. 7, three lines are drawn on the plots. The squares represent the monthly values each year, whereas the thick line shows the average rate for the 4 years. The two thin lines show SD. Values shown above and under the thick lines respectively represent greater and smaller monthly rates. Values shown above the upper thin line represent much larger monthly rates than usual, whereas values shown below the lower thin line denote much smaller monthly rates than usual.
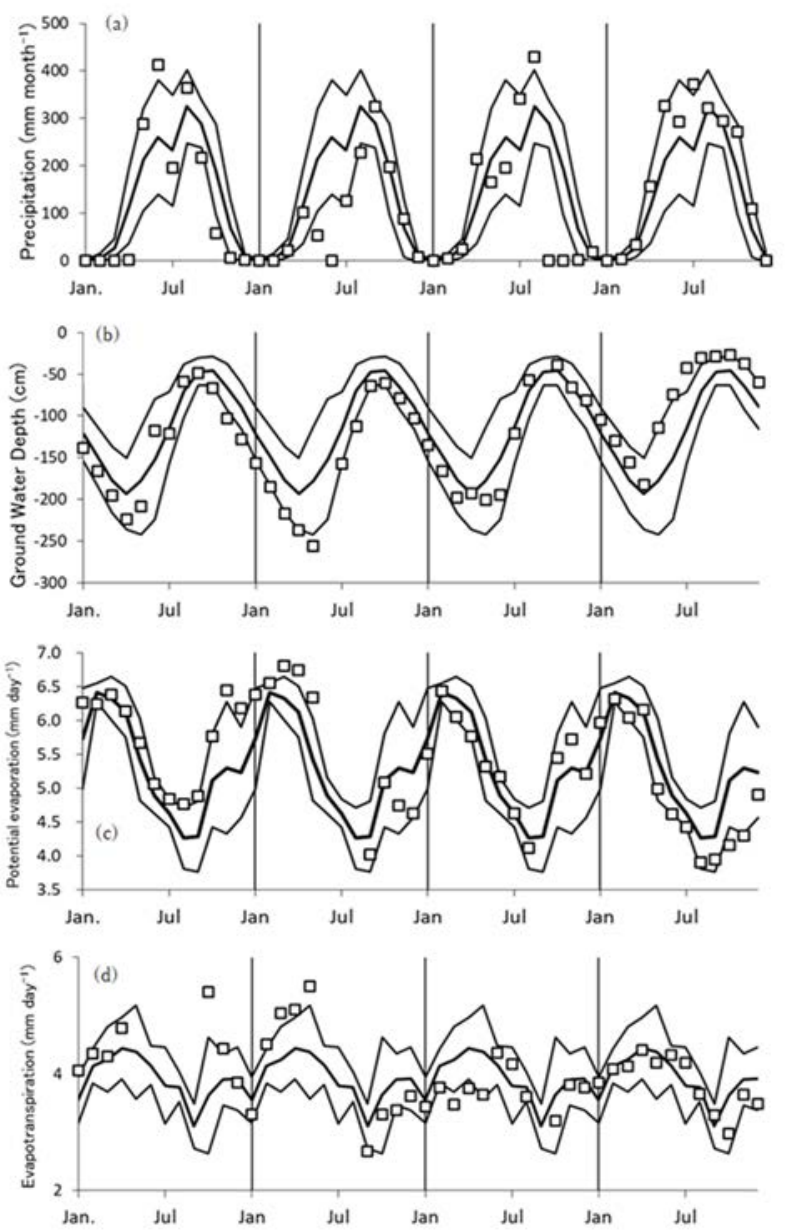

Figure 7: (a) The monthly precipitation; (b) Monthly averaged groundwater level; (c) Monthly averaged Ep; and (d) Monthly averaged E. The averaged rates (Ars; thick line) and standard deviations (SDs; thin lines) were calculated with these monthly rates in each month [5]. 
4.5 Comparing seasonal fluctuations in precipitation and groundwater level

Precipitation is mainly observed during the rainy season: April-October. The lowest groundwater levels of the year are observed in April and May, which mark the beginning of the rainy season. Therefore, water resources are regarded as tightest in April and May. The amounts of water resources at that time are expected to depend on the amount of precipitation in the rainy season of the prior year. For example, the lowest monthly average groundwater level was observed in May 2005 during the four years depicted in Fig. 7(b) because precipitation tended to be low in September-December 2004.

\subsection{Comparing groundwater level and potential evaporation and evapotranspiration}

As described in the preceding section, the annual lowest monthly averaged groundwater levels were observed in April of 2004 and 2007 and in May of 2005 and 2006. These months are regarded as the most severe water environment not only for human activities but also for forest trees. Therefore, we compared the monthly averaged daily potential evaporation and the monthly averaged daily evapotranspiration during the month when the groundwater level dropped the most in each year (Fig. 8). Potential evaporation is an index of the temporal variation of the climatic conditions that force evaporation. Trees, by contrast, close their stomata to prevent water loss when they run out of water. Therefore, when the soil is dry and trees cannot absorb a sufficient amount of water, the evapotranspiration rate decreases: when the tree cannot secure sufficient water from the soil, the amount of evapotranspiration decreases to a relative degree. However, in Fig. 8, four points are arranged in a straight line. Therefore, even during a month when the annual minimum monthly average groundwater level is observed, trees can secure sufficient water from the soil, so that photosynthesis and evapotranspiration can be performed without restrictions without closing the stomata. Fig. 9 presents a comparison of the annual minimum monthly average groundwater level with average daily evapotranspiration of the

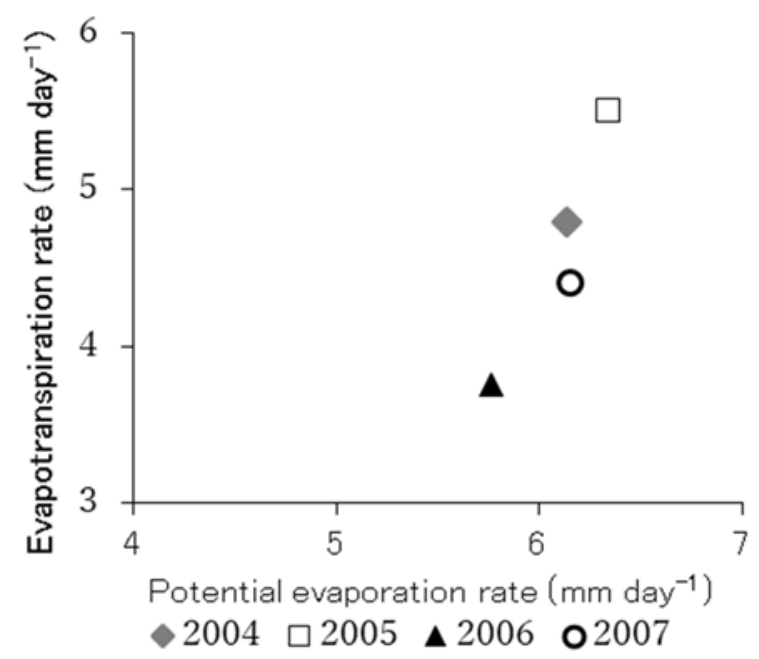

Figure 8: Comparison between the monthly averaged potential evaporation and the monthly averaged daily evapotranspiration during the month when the groundwater level dropped the most in each year. 


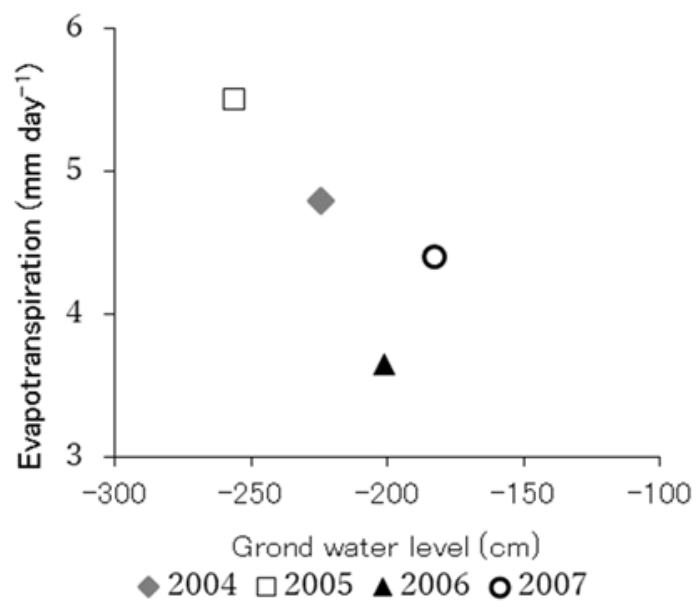

Figure 9: Comparison of the annual minimum monthly average groundwater level with averaged daily evapotranspiration of the same month.

same month. The monthly average daily evapotranspiration in May 2005, for which groundwater level was observed and which is apparently the most severe water environment, is higher than the monthly average daily evapotranspiration in the other three years. As discussed above, the dry evergreen forest examined for this study was judged as consuming water to the greatest extent potential with no restrictions.

\section{CONCLUSION}

This study examined the sustainability of groundwater as a water resource. Many agricultural areas around the world depend on groundwater for their water resources. The Great Plains of the United States are threatened because the groundwater level continues to drop as a result of excessive pumping of groundwater from the Ogallala Aquifer, which supplies water resources. In Kampong Thom, Cambodia, the subject of this report, dry evergreen forests consume water without limitation in the natural environment because, even though there is a long dry season, rainfall of several thousand millimetres invariably comes during the rainy season. A thick soil layer exceeding $10 \mathrm{~m}$ can store vast amounts of groundwater. Water consumption by plantations and crops is unlikely to exceed that of dry evergreen forest considerably. Therefore, we infer groundwater as a sustainable resource that is useful for stability even if dry evergreen forests are developed into plantations and agricultural lands. However, when groundwater is used for production other than plants, such as for industry and livestock, much more water may be consumed than by dry evergreens. In such cases, there is a possibility of groundwater depletion.

\section{REFERENCES}

[1] Ohnuki, Y., Shimizu, A., Chann, S., Toriyama, J., Kimhean, C. \& Araki, M., Seasonal change in thick regolith hardness and water content in a dry evergreen forest in Kampong Thom Province, Cambodia. Geoderma, 146, pp. 94-101, 2008.

[2] Shimizu, A. et al., Runoff characteristics and observations on evapotranspiration in forest watersheds, central Cambodia. Forest Environments in the Mekong River Basin, eds H. Sawada et al., Springer-Verlag: Tokyo, pp. 135-146, 2007. 
[3] Nang, K. et al., Determination of seasonal change from dry to rainy using wind and precipitation data - Case study of Kampong Thom, central Cambodia. Proceedings of 8th International Workshop on Forest Watershed Environment Research in Cambodia, pp. 11-14, 2012.

[4] Penman, H.L., Natural evaporation from open water, bare soil and grass. Proceedings of the Royal Society of London A, 193, pp. 120-145, 1948.

[5] Chann, S. et al., Interannual variation in the evapotranspiration of an evergreen forest in Kampong Thom, central Cambodia. Proceedings of International Workshop on Forest Research in Cambodia, pp. 21-24, Nov. 2011. 